\title{
Research status and trend of comprehensive technology for Multi-storey transportation hub construction
}

\author{
Jing-xian $\mathrm{SHI}^{1, *}$ \\ ${ }^{1}$ Oxbridge College, Kunming University of Science and Technology, Kunming, Yunnan, 650106, China
}

\begin{abstract}
With the development of China's transportation industry, a lot of expressways have been built, and Multi-storey transportation hubs are built for the interchange of high-speed. Due to the limitation of terrain and traffic, there are many spans in the interchange Multi-storey transportation hub, which has a tight construction period and a great difficulty in construction organization. This paper first sorts out the development and research of comprehensive technology of Multi-storey transportation hub construction at home and abroad, and then analyzes and summarizes the research of Multi-storey transportation hub construction at present, the application research of Swivel Construction Technology in hub project, and the application status of BIM Technology in Multi-storey transportation hub project.
\end{abstract}

\section{Introduction}

With the development of China's transportation industry, many expressways have been built. In order to connect all directions of the road network, more and more Multistorey transportation hubs have been built. Transportation hub is an important part of national or regional transportation system. It is the intersection of different transportation modes of transportation network and transportation lines. It undertakes the functions of through operation, transfer operation, hub operation and urban external transportation. Hub projects are often difficult to construct, and because they may span roads and railways in operation, they need to be constructed quickly. There are more and more comprehensive technical researches on the construction of Multi-storey transportation hub.

\section{Research status of Multi-storey transportation hub construction}

Foreign studies usually focus on the comprehensive evaluation of the involved road sections from the perspective of the analysis of the actual traffic volume and traffic conflict inducing factors. After obtaining the measured data, they usually adopt certain evaluation indexes and establish the road section data model to carry out countermeasures research.

For example, JP $\mathrm{Moon}^{[3]}$ studies that a reasonable number of lanes at the dense on ramp and an auxiliary lane at the congested on ramp will increase the potential safety hazard of the merging area, and puts forward lowcost countermeasures. Richard w. Lyles and Virginia P. ${ }^{[2]}$ sisiopiku studied the influencing factors and standards of speed control in expressway operation area. In the same year, Jerry L. Graham and James Migletz ${ }^{[3]}$ and others studied the speed limit standards of construction sections, and established the relationship with the speed limit value from the aspect of traffic safety.

Most of the foreign researches on the traffic organization during the construction of Expressway start from the traffic flow and the expected traffic conditions during the construction period. After obtaining the measured data of the same type of section, the corresponding road traffic model is established by selecting the quantitative analysis and other evaluation indexes. In order to avoid the impact on the normal traffic of the construction section, it is necessary to predict the possible traffic flow confluence state and traffic conflict inducing factors in the follow-up construction process, so as to determine the corresponding traffic organization design.

At present, the main research results in China mainly focus on the exchange research and analysis of interchange confluence area, construction model establishment and data analysis, and Construction Research of traffic organization in construction area. According to the current situation and problems of national highway construction, the traffic construction organization has developed rapidly and achieved certain results.

Zhang Peng ${ }^{[4]}$ and others analyzed and optimized the scheme of cast-in-place support system of specialshaped box girder in the process of cross construction of Multi-storey structure in limited space, and adopted BIM The technology simulates the collision inspection between temporary support system and adjacent structure, 3D visualization technology disclosure and construction process, which solves the technical problems of cross construction in limited space and mutual interference of multi-layer structure construction, and plays a good reference role in the promotion and

\footnotetext{
* Corresponding author: sara_shivip@163.com
} 
application of BIM Technology and the construction of similar projects.

In the study of traffic organization design for reconstruction and expansion of expressway, $\mathrm{Xu}$ Dianfeng ${ }^{[5]}$ carried out traffic organization design item by item by determining the way of sectional construction organization design, strengthened the emergency plan for traffic accidents during construction, and released traffic information in time.

In the analysis of traffic organization and traffic protection scheme in expressway reconstruction and expansion construction, Guizhen[6] et al. From the perspective of theoretical research, focus on grasping the traffic organization principle in reconstruction and expansion construction period, determine the traffic protection scheme in construction period, and ensure the smooth flow of construction section by improving traffic organization measures.

Some construction organization experience has been accumulated in the reconstruction and expansion of expressways in China, such as Shenyang Dalian Expressway, Shanghai Hangzhou Ningbo Expressway, Guangzhou Foshan expressway, Shanghai Nanjing Expressway, etc., but a relatively mature theoretical system has not been formed. The construction organization of construction section is a complex system engineering, involving construction sequence, engineering technology, management control and other disciplines.

\section{Research status of application of Swivel Construction Technology}

Swivel construction is an important construction method for the special span of Multi-storey transportation hub. The swivel construction of bridge began in the 1940s. Foreign scholars took the lead in the discussion and research of swivel construction technology, and the vertical swivel method was first applied. In 1947, France built the world's first swivel bridge, with a main span of 110 meters and vertical rotation method. In the 1950s, the Arentobel bridge with a span of $150 \mathrm{~m}$ in Germany and the DOMS River Bridge with a span of $70 \mathrm{~m}$ in Italy were constructed by vertical rotation method. Then, in the foreign cable-stayed bridge, $\mathrm{T}$-shaped rigid frame bridge, continuous beam bridge, arch bridge and other bridge types, the use of horizontal rotation method is more and more widely, and the technology is more and more mature. ${ }^{[7-8]}$

The invention of bridge swivel construction technology makes the application scope of bridge engineering more extensive, reduces the limited conditions of bridge construction, and promotes the development of bridge engineering. The swivel construction technology started relatively late in China. In 1975, the research on swivel bridge technology was started, and the first horizontal rotation construction bridge in Chinese history was completed in 1977.

Sichuan Provincial Highway Planning and Design Institute's research on "double box symmetrical synchronous Swivel Construction Technology of arch bridge" is very representative, and the bridge with main span of $122 \mathrm{~m}$ is a successful case of this method. And the successful application also represents that the domestic bridge swivel construction technology has become increasingly mature. In 2000, the Yajisha CFST(Concrete Filled Steel Tube) arch bridge in Guangzhou was successfully rotated, which represents a major breakthrough in the field of Swivel Construction Technology in China. In 2016, the main bridge on the east side of Danyang Road overpass in Heze, Shandong Province, broke the world record for the weight of swivel bridge, and became the largest cable-stayed bridge with swivel weight in the world. At the same time, it became the longest bridge with single spherical hinge rotation construction in the world, with swivel length of $238 \mathrm{~m}$ and self weight of 24800 tons. In 2018, Baoding Lekai Street bridge broke the record of swivel weight of the main bridge on the east side of Danyang Road overpass in Heze, Shandong Province with a swivel weight of 48000 tons. China's swivel bridge construction is constantly breaking new records, and the bridge swivel construction technology has made a major breakthrough, which is at the world's leading level.

\section{Application status of BIM Technology in Multi-storey transportation hub project}

BIM Technology originated in the United States. In 2002, Autodesk company developed a BIM software platform, which promoted BIM from the concept stage to the application stage, and also ushered in a new revolution in the construction industry. For example, the United States published the first edition of the national BIM standard in 2007, followed by the second and third editions in 2012 and 2015; < Singapore BIM guide version 1.0> was published in 2012; and the UK[9] BIM standard for construction industry was published in 2009, which was published in June and September 2011 respectively BIM standard based on Revit and Bentley platform was released in June, and $<$ AEC (UK) BIM > protocol v2.0 was released in 2012; < Jia BIM Guide $>$ (first edition and second edition) was released in Japan $^{[10]}$ in 2012 and 2015 respectively; <BIM Application guide in construction field $>$ was released in South Korea in 2010.

Wang Xin-tang ${ }^{[11]}$ and others deeply discussed the application of BIM Technology in expressway project construction. According to the characteristics of project structure, construction organization and management, According to the specific needs of the project, select the key objects to carry out BIM modeling, model application, and deploy the management system based on BIM. Through the comprehensive application of BIM Technology, realize the refinement of design and construction, improve project quality, improve quality and efficiency, and adopt BIM Technology, such as visualization, coordination, simulation, optimization and other characteristics, fully make up for many shortcomings in the design, construction and management at this stage, and effectively improve the 
problems and deficiencies in infrastructure construction. Complete BIM modeling, model application, and deploy BIM based management system. Through the comprehensive application of BIM Technology, gradually achieve the goal of fine construction and fine management of the project, and achieve the purpose of improving project quality, increasing efficiency and reducing cost.

In 2014, China issued the <Building Information Model Design Standard of Civil Building (DB11/10632014)>, which is the first BIM application standard in China, pushing the application of BIM Technology to a new height; In December 2015, the youth BIM development alliance of Shanghai Construction and transportation industry, jointly sponsored by Shanghai Construction Engineering Co. Ltd. tunnel Co. Ltd. China Construction Eighth Bureau, Shen-tong Metro, modern design and Tong ji construction, was officially established, which will jointly promote the promotion and application of BIM Technology with the rotation responsibility system; In June 2018, Wang Chang-jin, deputy chief engineer of China Railway Design Group Co., Ltd. and national engineering survey and design master, gave a detailed introduction to the BIM research of China Railway at the world Transportation Conference "BIM Technology Innovation and Application Forum in the field of transportation".

Although domestic BIM Technology started late, many experts, scholars and enterprises devoted themselves to the research of BIM, which played a crucial role in the development of BIM Technology. For example, according to the characteristics and actual needs of construction management in China, Zhang Jianping $^{[3]}$ put forward the technical framework, system process and Countermeasures of BIM application in engineering construction, and combined BIM with 4D to establish the management and modeling system of engineering project. Through the application of practical engineering, its rationality was verified.

In the construction process of Multi-storey transportation hub bridge, the finite element analysis software is used to simulate the bridge beam construction, and then the BIM management platform is used to manage the engineering materials. The application of BIM Technology has good effect in saving and efficient management of materials.

\section{Research trend of comprehensive technology for Multi-storey transportation hub construction}

According to the research status and the accumulation of knowledge, the research on the comprehensive technology of Multi-storey transportation hub construction can have the following research points.

(1)Research on fast comprehensive construction organization technology of Multi-storey interchange hub, construction organization and network plan based on space and time; Based on the efficient communication technology of information and network, BIM information technology combined with construction organization design is used to establish the sub information model of construction process optimization to realize the optimization of construction organization. Based on the on-site video, settlement sensing and other monitoring technology progress, quality control method research; according to the project on safety, quality, construction period, cost, the influence of business line and other factors, compare and determine the reasonable overpass construction scheme.

(2)Research on traffic relief and safety evaluation across existing high-speed business lines. If the new transportation hub needs to cross the roads and railways in operation, it is very important to study the synchronous cooperation method of the construction site; based on the relevant theoretical knowledge, according to the specific traffic situation of the interchange of Yuxi hub, this paper puts forward a reasonable traffic relief scheme. The paper identifies, analyzes and evaluates the safety risk of construction, gives the risk response strategies according to the results of safety risk assessment, and puts forward the risk countermeasures combined with the current situation of safety risk management of construction projects in China. Traffic relief and emergency plan, safety monitoring and early warning mechanism, etc.

(3)Based on BIM Technology, the rapid construction technology of Multi-storey traffic hub swivel bridge is studied, including the key technology and benefit of BIM application in swivel construction; research on safety control and monitoring method of swivel construction; construction visualization and coordination linkage method of various professional types of work; research on safety and stability of temporary support, etc. This paper summarizes and uses BIM information technology combined with construction organization design to establish construction process optimization sub information model, realize construction organization optimization, and swivel visual construction simulation of relevant BIM software.

\section{Conclusion}

According to the current development of Multi-storey hub construction at home and abroad, this paper summarizes the rapid comprehensive construction technology of Multi-storey transportation hub in complex environment, and then puts forward some further research directions according to the research status. There are many researches on the rapid construction of Multi-storey hub. With the development of transportation, the research results will continue to update and deepen. It is particularly important to write the comprehensive technical construction guide and construction method for the rapid construction of Multistorey transportation hub, which can provide reference and basis for the construction of similar projects. 


\section{References}

1. JP Moon,PEMP Reese, JH Dunlop Pe.Evaluation of Operations and Safety in a Congested Freeway Merging Area with Auxiliary through Lane[C]. Transportation Research Board Meeting,(2012).

2. Virginia P. Sisiopiku, Richard W. Lyles, Main Krunz, Qingyan Yang, Darcin Akin, Mousa Abbasi. Study of Speed Patterns in Work Zones In:Preprints of the Transportation Research Board 78th Annual Meeting.Washington D.C.January,34-45.

3. Ames Migletz,Jerry L.Graham.Work Zone Speed Limit Procedure.In Preprints of the Transportation Research Board 78th Annual Meeting. Washington D.C.January,24-30.

4. Zhang Peng,Yang Fan,Li Chunyong. Key Technology Research of Special-shaped Box Girder Construction under Multilayer Interchange Condition[J]. Municipal Engineering Technology. 2018, 36(6):48-56.

5. XU Dianfeng. Study on traffic organization design of reconstructed and expanded Expressway[J]. Engineering and construction. 2011,25(5):690-692.

6. GUI Chong CUI Tong. Analysis of traffic organization and traffic protection scheme in expressway reconstruction and expansion construction [J]. SCIENCE \& TECHNOLOGY INFORMATION. 2019,9: 367-405.

7. H Wakabayashi, Y Takahashi, S Niimi, K Renge. Traffic Conflict Analysis using Vehicle Tracking System/Digital VCR and Proposal of a New Conflict Indicator [J].Doboku gakkai ronbunshuu D, 2003,20:949-956 .

8. Tarek Sayed, Sany Zein.Traffic conflict standards for intersections[J]. Transportation Planning \& Technology,2007,22(4):309-323.

9. William East E,Nisbet N,Liebich T.Facility management handover model view[J].Journal of Computing in Civil Engineering,2013,27(1):6167.

10. Cao Zaixing. The Research on BIM Technology Applied to the Bridge Maintenance Management[D] Chongqing: Chongqing Jiaotong University ,(2017).

11. WANG Xintang. Application of BIM technology in the construction of ningliang expressway project. [D]. SHANDONG: SHANDONG UNIVERSITY (2019). 